\title{
Princípios do Sistema Único de Saúde (SUS) e a humanização das práticas de saúde
}

Tornou-se comum entre nós designar, por princípios e diretrizes do SUS, as linhas mestras delineadas no texto da constituição federal: a universalidade, a equidade, a integralidade, a descentralização, a participação da população e a organização da rede de serviços de modo regionalizado e hierarquizado. Tais princípios e diretrizes foram forjados no interior de um processo de luta travada pelo movimento da Reforma Sanitária desde o final dos anos setenta. Este movimento (por vezes chamado simplesmente de movimento sanitário), embora não homogêneo, produziu um amplo consenso em torno de princípios básicos que deveriam nortear a atuação do Estado na saúde, a começar pela inequívoca afirmação de que a saúde deveria ser considerada como um direito de todos e um dever do Estado, seguindo por uma compreensão bastante ampliada da saúde e de seus determinantes sociais, bem como por uma visão bastante ampliada das responsabilidades do Estado para com a saúde. Tal movimento também formulou os princípios que deveriam nortear a construção de um sistema de saúde, sendo estes os elementos centrais que comumente chamamos de princípios e diretrizes do SUS.

Mas, se o texto constitucional efetivamente incorporou algumas das aspirações do movimento da Reforma Sanitária, certamente não reconheceu todas elas. Como produto de um processo de negociação travado na arena da Assembléia Constituinte, a constituição promulgada em 1988 delineou um contexto para o SUS que, não necessariamente, era o imaginado pelo movimento sanitário, ou pelo menos não consensual em seu bojo (como na ampla liberdade para a iniciativa privada na saúde, e o caráter fortemente municipalista do pacto federativo). Por sua vez, no processo de negociação, algumas questões polêmicas foram deixadas para ser detalhadas posteriormente, como foi o caso da questão sobre o financiamento do SUS, tratada no texto original de modo excessivamente genérico.

A Constituição criou o SUS. Mas sua implementação se fez em um contexto político também bem distinto do imaginado pelo movimento sanitário: no cenário internacional, crescia a difusão do ideário neoliberal, com as propostas de redução da atuação do Estado em vários setores, inclusive na saúde; no cenário nacional, o restabelecimento das eleições diretas levou à presidência governos que efetivamente incorporavam, de modo significativo, aquele ideário de redução da atuação do Estado. A luta em defesa do SUS (para usar uma expressão difundida pelo recente Pacto de Gestão) e de seus princípios e diretrizes tomou novos

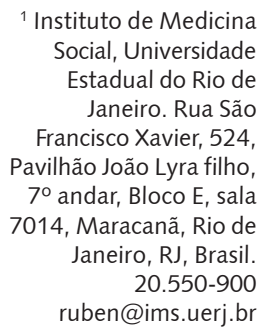

${ }^{1}$ Instituto de Medicina Social, Universidade Estadual do Rio de Janeiro. Rua São Francisco Xavier, 524, Pavilhão João Lyra filho, $7^{\circ}$ andar, Bloco E, sala 7014, Maracanã, Rio de Janeiro, RJ, Brasil. 20.550-900 ruben@ims.uerj.br 
rumos, incluindo novos atores (como o CONASS e o CONASEMS, assim como os atores participantes de Conselhos e Conferências de Saúde). O SUS que foi se desenhando no concreto da vida dos brasileiros nem sempre correspondia (e corresponde) ao ideário do movimento sanitário, embora sejam inequívocos os avanços produzidos nesses vinte anos.

Ao longo desse processo de luta, nem sempre os diversos princípios e diretrizes do SUS foram tratados com igual importância. Ao contrário, em cada conjuntura, certa hierarquia de importância se constituía entre eles, quer como reflexo da heterogeneidade dentro do movimento sanitário no que diz respeito à importância dada a este ou aquele princípio, quer em decorrência das opções estratégicas diante de determinados obstáculos políticos.

Este pequeno texto procura examinar, ainda que de modo exploratório, as relações entre esses chamados princípios do SUS e as questões de transformação das práticas de saúde. Procura apreender, por um lado, as oscilações da centralidade destas últimas questões ao longo do tempo, bem como as dificuldades que ainda hoje se colocam para sua concretização. Tomo aqui os princípios e diretrizes do SUS, portanto, não como definições estáticas, mas como signos dos valores pelos quais temos lutado e, creio eu, pelos quais vale a pena lutar.

\section{Da questão democrática ao imperativo da mudança das práticas de saúde no SUS}

Tomo, como primeira aproximação das diferentes perspectivas como a transformação das práticas de saúde foi sendo tratada no bojo do movimento sanitário, um contraste entre dois documentos: um datado de 1979, intitulado $A$ Questão Democrática na Área de Saúde (CEBES, 1980), e outro intitulado O SUS pra valer: universal, humanizado e de qualidade (Fórum da Reforma Sanitária, 2006), escrito em julho de 2006, ambos voltados a alimentar um debate junto ao Legislativo $^{2}$

O primeiro documento pode ser considerado uma das primeiras apresentações sistemáticas do que, posteriormente, veio a se constituir como os princípios do SUS. Contudo, nele a questão da transformação das práticas de saúde não aparece como questão central das políticas de saúde. A idéia de integralidade, por exemplo, não é explicitamente mencionada no documento (apesar de haver rápida menção sobre a articulação entre assistência e prevenção na atenção primária).

É claro que se reconheciam, naquele texto, os signos de uma profunda crise na medicina de então e na organização das práticas: denunciavam-se a má qualidade da assistência, as filas, o seu alto custo. Contudo, essas mazelas eram atribuídas a características das políticas de saúde da época, consideradas privatizantes e favorecedoras da mercantilização da saúde:

Entretanto, o que só recentemente está vindo à luz, em forma ainda tanto encoberta, são as reais causas das distorções detectadas. As raízes últimas da anarquia instaurada na assistência médica e da insolvência sanitária da população: a mercantilização da medicina promovida em forma consciente e acelerada por uma política governamental privatizante, concentradora e anti-popular. (CEBES, 1980, p.11)

Ao subordinar a má qualidade da atenção médica às características das políticas governamentais de cunho tecnocrático, autoritário, centralizador e privatizante, o

\author{
2 O primeiro texto foi \\ apresentado pelo CEBES \\ no $1^{\circ}$ Simpósio sobre \\ Política Nacional de Saúde \\ na Câmara Federal em \\ outubro de 1979. 0 \\ segundo foi elaborado \\ pelo Fórum da Reforma \\ Sanitária, que congrega, \\ além do CEBES, a \\ ABRASCO, a AMPASA, a \\ AMBRES e a Rede \\ Unida, e foi apresentado \\ para discussão com a \\ Frente Parlamentar da \\ Saúde e com outras \\ entidades do setor de \\ saúde e de educação, \\ assim como com a \\ sociedade em geral.
}


documento manifesta, tacitamente, a expectativa de que a qualidade se estabeleceria: com a mudança radical nesta política, com um processo de democratização possibilitado pela articulação entre a descentralização e a participação popular, e com o fortalecimento dos serviços públicos e a valorização dos profissionais de saúde que neles atuam. Pouca ou nenhuma atenção é dada a outras mediações na produção da má qualidade da assistência como, por exemplo, dadas pelas características da formação dos profissionais de saúde ou pela própria racionalidade médica que, de algum modo, orientava as práticas dos profissionais de saúde. Em consequência, a transformação dessas práticas assistenciais não era vista como objeto de políticas de saúde, ou melhor, o tema da transformação das práticas de saúde não era central para as políticas de saúde que se desenhavam.

Esta interpretação dos determinantes da má qualidade das práticas assistenciais guarda profunda relação com as estratégias políticas assumidas na época, voltadas para a construção da base de consensos interna ao movimento sanitário (talvez suprimindo algumas questões que, embora postas na base acadêmica daquele movimento nascente, não eram tão consensuais) e externa ao movimento. Este último aspecto se expressa tanto no título, que põe em destaque a questão democrática, tão cara ao movimento de oposição ao governo militar, como no fato de o documento apoiar explicitamente algumas das reivindicações dos movimentos sociais para além da área da saúde.

Façamos um contraponto com o segundo documento, de 2006. Seu título já indica uma grande inflexão: o SUS pra valer parece ser caracterizado pelo seu caráter universal, e pelas características de suas práticas, humanizadas e de qualidade. Mais do que isso, reconhecem-se as contradições e os limites concretos do SUS que temos, diante dos imperativos ético-políticos da universalidade, da humanização e da qualidade. Em um trecho, afirma-se: "O SUS universal, cujo melhor exemplo é o programa de AIDS - cartão de visitas de diversos governos -, convive com avaliações negativas sobre o acesso e as condições indignas do atendimento efetuado pela rede de serviços de saúde" (Fórum da Reforma Sanitária, 2006, p.387).

Aqui, reconhece-se a má qualidade de práticas de saúde no âmbito do SUS real:

Os brasileiros em busca de assistência e cuidados à saúde na rede do SUS são submetidos a filas que se formam desde a madrugada para pegar senhas, passam por triagens, aguardam horas em locais de espera, freqüentemente desconfortáveis, e necessitam, quase sempre, percorrer mais de um estabelecimento nos casos exigentes de realização de exames e obtenção de medicamentos. A lógica que deve orientar a organização dos serviços de atenção e atuação dos profissionais da saúde é a de tornar mais fácil a vida do cidadãousuário, no usufruto de seus direitos. Trata-se de organizar o SUS em torno dos preceitos da promoção da saúde, do acolhimento, dos direitos à decisão sobre alternativas terapêuticas, dos compromissos de amenizar o desconforto e o sofrimento dos que necessitam assistência e cuidados. (Fórum da Reforma Sanitária, 2006, p.387)

Nesse sentido, defende-se uma mudança radical das práticas e dos modos de organização dos serviços de saúde:

A sustentabilidade político-econômica do SUS e sua legitimidade dependem da promoção de mudança radical do modelo de atenção, pois a qualidade e a resolutividade das ações e serviços de saúde possibilitarão ao SUS tornar-se patrimônio nacional e ser o local preferencial de atendimento para todos os segmentos sociais. (Fórum da Reforma Sanitária, 2006, p.389)

O entendimento aqui desloca-se da análise dos determinantes das práticas para afirmar o próprio imperativo ético-político, advertindo sobre as possíveis consequências de sua não-realização: a própria sustentabilidade e a própria legitimidade do SUS é que estão em questão. Portanto, impõe-se uma mudança radical:

Uma mudança radical do modelo de atenção à saúde envolve não apenas priorizar a atenção primária e retirar do centro do modelo o papel do hospital e das especialidades, mas, 
principalmente, concentrar-se no usuário-cidadão como um ser humano integral, abandonando a fragmentação do cuidado que transforma as pessoas em órgãos, sistemas ou pedaços de gente doentes. As práticas interativas, mais holísticas, devem estar disponíveis como alternativas de cuidado à saúde. A humanização do cuidado, que envolve desde o respeito na recepção e no atendimento até a limpeza e conforto dos ambientes dos serviços de saúde, deve orientar todas as intervenções. (Fórum da Reforma Sanitária, 2006, p.389)

Note-se que humanização e qualidade, evocadas como centrais para a sustentabilidade e legitimidade do SUS, não são princípios do SUS naquele sentido que indicamos anteriormente aos princípios reconhecidos no texto constitucional, mas tornam-se centrais para as políticas de saúde. É claro que as aspirações de mudanças radicais no modelo assistencial anunciadas nesse documento guardam relações com a aspiração de integralidade, pelo menos em alguns de seus sentidos.

Em outro trabalho (Mattos, 2001), analisei os sentidos do termo integralidade presentes no debate sobre a saúde antes da promulgação do texto constitucional. Mostrei a existência de, pelo menos, três grandes grupos de sentidos: um como atributo das práticas dos profissionais de saúde, outro como atributo dos modos de organizar os serviços de saúde, e o terceiro como atributo das políticas de saúde. Sentidos que têm em comum uma recusa ao reducionismo, mas que nem sempre tiveram, ao longo do tempo, a mesma centralidade no movimento sanitário. De especial importância para a presente discussão são as oscilações na centralidade nas noções de integralidade voltadas para as práticas e para a organização dos serviços. É nesse sentido que podemos compreender que, na conjuntura em que a questão da transformação das práticas no SUS parece se tornar mais central no debate das políticas de saúde, a evocação de alguns dos valores expressos outrora na perspectiva da integralidade se expressem utilizando outros vocabulários. Mais importante do que examinar essas escolhas de vocábulos, é compreender as oscilações da centralidade da temática da transformação das práticas, quer sejam elas decorrentes das tensões e eventuais contradições internas ao movimento sanitário, quer sejam elas decorrentes das estratégias adotadas em resposta a conjunturas particularmente adversas.

O contraponto dos dois documentos indica uma inflexão na reflexão do chamado movimento sanitário. Para melhor compreendê-la, talvez seja oportuno reexaminar, na própria trajetória do movimento sanitário antes da Constituição de 1988, os elementos contraditórios que nos permitam apreciar as diferentes centralidades das perspectivas de mudança das práticas ao longo de algumas conjunturas. Tomo aqui um recorte de privilegiar a vertente acadêmica do movimento sanitário.

\section{O tema da transformação das práticas na trajetória do movimento sanitário}

O chamado movimento de Reforma Sanitária no Brasil organizou-se como uma ampla frente em torno de um conjunto de objetivos (poderíamos, sem grandes riscos, dizer imagens-objetivo). Contudo, esta frente nunca foi plenamente homogênea. Podemos identificar, em sua origem, pelo menos três vertentes distintas. De um lado, uma vertente originária da Saúde Pública, mas não da velha Saúde Pública moderna, que era centrada na doença, tendo a administração científica como fundamento da sua ação, e muito próxima da medicina das doenças infecto-parasitárias e dos modelos de intervenção norte-americanos. A Saúde Pública que concorreu para o movimento sanitário trazia consigo os ventos do desenvolvimentismo. Esta vertente enfatizava a necessidade de se compreenderem as relações entre a saúde e o desenvolvimento econômico e social; defendia o planejamento como central na atuação do Estado na saúde, e abria-se para as teses que buscavam a articulação entre a Saúde Pública e a assistência médica. A segunda vertente, a Medicina Preventiva, instalada nos departamentos de mesmo nome, tampouco derivava linearmente das bases postas por Level e Clark nos Estados Unidos. De fato, aqui no Brasil, nos anos 70, desenvolveu-se densa crítica àquela Medicina Preventiva, exemplificada pelo trabalho de Arouca, $O$ dilema preventivista. A terceira vertente buscava retomar o ideário da Medicina Social, que, enquanto disciplina, havia perdido o prestígio que teve nos 1800, logo após o advento da microbiologia (e, em seguida, da moderna Saúde Pública). No início dos anos 1970, reliam os princípios da Medicina Social para afirmar: 1) que a saúde deveria ser vista como uma responsabilidade do Estado; 2) que as condições de saúde e da doença tinham profundas relações com 
as condições econômico-sociais, relações essas que deveriam ser objeto de estudo; e 3) que as ações e intervenções médicas deveriam ser tanto propriamente médicas como sociais.

As intensas trocas entre estas vertentes no momento da constituição do movimento sanitário permitiram um grande hibridismo entre elas, criando as condições para a elaboração de um projeto amplamente consensual. Contudo, algumas diferenças significativas persistiram, embora assumindo algumas configurações distintas ao longo dos anos 1980 e 1990. Um dos temas mais tensos foi o relativo às práticas e as instituições médicas. Evoco - sem a pretensão de analisá-los em detalhe - alguns signos dessa tensão contínua. O primeiro, produzido originalmente no seio da vertente da Medicina Social, resultou do profundo impacto das conferências de Michel Foucault feitas ainda em 1974 no Brasil. Derivou-se dela uma dialética entre duas posições distintas: de um lado, uma densa análise crítica das instituições médicas, e das suas práticas, que, aliás, foi intensamente apropriada e utilizada no movimento da reforma psiquiátrica. Nessa mesma vertente, aprofundaram-se as críticas à racionalidade médica, em um processo que, pelo menos em alguns lugares, aproximou-se bastante da chamada medicina integral. Devemos destacar, nessa perspectiva, as críticas às formas como profissionais de saúde exercem seu poder sobre os outros, em estratégias de subordinação do outro a uma ordem médica. De outro lado, os que enfatizavam a gravidade da não-garantia pelo Estado do acesso universal à assistência médica quando ela se fizesse necessária. Nessa perspectiva, defendia-se a expansão da assistência médica garantida pelo Estado, ainda que esta fosse marcada pelas instituições e práticas densamente criticadas pela primeira vertente. A dinâmica dessa dialética indicava um caminho teoricamente consensual: ampliar o acesso à assistência médica e, ao mesmo tempo, transformar suas práticas. Tese de difícil operacionalização. Voltaremos a ela mais adiante.

Um segundo signo foi dado pela tese operacional, fortemente influenciada pela estratégia de ocupação dos espaços institucionais, bastante em voga à época, de que significativos avanços poderiam ser feitos a partir da atuação técnico-política nos níveis da gestão, tanto nas instituições da Saúde Pública, como nas instituições da assistência médica. Esta tese, entretanto, assumiu diferenças sutis conforme o lócus institucional dessa ocupação. Desde a Saúde Pública, a estratégia voltava-se para que sanitaristas assumissem a gestão das unidades de saúde, passando a controlar o trabalho médico e dos demais profissionais de saúde que atuavam nas tradicionais unidades de Saúde Pública. Isto ao mesmo tempo em que transformavam estas unidades em serviços mais aptos a responderem ao que pareciam ser as reais necessidades de saúde da população. A epidemiologia (mas também um pouco o planejamento) surgiu ofertando os fundamentos da ação controladora dos sanitaristas sobre as práticas nos níveis de unidades mais básicas. Desde a assistência médica da previdência social, tratava-se de aproveitar médicos e enfermeiros que tinham tido alguma formação em Saúde Coletiva, deslocando-os da ponta da assistência para as práticas de gestão sistema, buscando ordená-lo para que o mesmo se voltasse para ampliar o acesso e, assim, responder às necessidades da população. O planejamento (mas também um pouco da epidemiologia) serviu de base para a condução técnico-política das transformações em hospitais e ambulatórios especializados no âmbito do Inamps. Particularmente importante para os propósitos deste trabalho é destacar as diferenças, sutis mas significativas, entre estas duas vertentes: por um lado, uma maior ênfase nas ações de prevenção (ou melhor, nas ações programadas pelos serviços de saúde) e na atenção básica; por outro, uma maior ênfase na necessidade de dar resposta ao sofrimento manifesto, e na necessidade de ampliar o acesso aos procedimentos considerados então de maior complexidade.

Um terceiro signo foi a divisão nas táticas (e depois nas estratégias de atuação) surgidas após o fracasso retumbante do Prev-saúde, e a abertura de possibilidades de desencadear uma estratégia de mudança do sistema de saúde sob a batuta da Previdência, que controlava grande parte da assistência médica no país. Espaços que permitiram, um pouco mais adiante, já na abertura política (embora ainda sem as eleições diretas), uma atuação do movimento em duas frentes: a da condução da reforma desde o Ministério da Saúde, e a da condução da reforma desde a assistência médica previdenciária. Frentes que se afastaram, até a grande polaridade gerada sob a divergência quanto ao processo de unificação, que já foi descrita como uma disputa entre os reformistas da saúde e os reformistas da Previdência (Baptista, 2007).

O quarto signo, um pouco em função daquelas estratégias políticas de ocupação de espaços, foi o gradual afastamento da formação na área de Saúde Coletiva da formação médica. A decisão de retirar, 
da formação dos residentes de medicina preventiva e social, as atividades de atendimento médico, com honrosas resistências pontuais, contribuíram para formar quadros de sanitaristas que definitivamente não compreendiam a assistência médica, não refletiam sobre ela ou sobre sua transformação. Um último signo, ligado ao anterior, foi o gradual afastamento do tema das transformações no ensino da medicina (e das demais profissões de saúde) da centralidade da agenda do movimento sanitário, mais ocupado progressivamente com a gestão do sistema. Devemos notar que, em parte em decorrência do movimento da medicina integral, foram-se desenhando em várias universidades propostas de mudanças no ensino, numa tentativa de modificar as posturas dos profissionais de saúde em suas práticas, afastando-os da excessiva especialização e da redução do sujeito à lesão.

Tais iniciativas estiveram, de certo modo, próximas ao movimento sanitário, na medida em que instituições de Saúde Coletiva organizavam, nos anos oitenta, sob a égide da chamada medicina comunitária, experiências alternativas em unidades de saúde próximas a comunidades marginalizadas. Em muitas delas, a assistência prestada era realizada por residentes de medicina preventiva, ou por internos, sendo espaços da tentativa de desenvolver uma medicina mais integral. Contudo, na medida em que as arenas de luta do movimento sanitário se deslocaram das experiências alternativas para os espaços institucionais na saúde pública ou na previdência, e o perfil dessa militância sanitária assumiu a perspectiva de uma atuação mais profissional (do sanitarista nos espaços da saúde pública, ou do gestor nos espaços da previdência), o tema da transformação da formação perdeu espaço na agenda.

Em conjunto, estes signos nos permitem sugerir que o tema da transformação das práticas de saúde, embora presente no debate, não alcançou uma centralidade muito grande na agenda nem foi crucial no amplo consenso do movimento sanitário antes da constituição. Compreende-se, assim, que, mesmo reconhecendo um imperativo ético-político da transformação das práticas de saúde no SUS, persistiam diferentes entendimentos dentro de segmentos tradicionalmente ligados ao movimento sanitário acerca da importância de tais transformações para o SUS.

\section{Para além da universalização e da igualdade: por um SUS humanizado, de qualidade e com integralidade}

Além de uma certa heterogeneidade no âmbito do próprio movimento sanitário, devemos reconhecer que as aspirações desse movimento não foram integralmente atendidas. Tampouco o contexto de implantação do SUS nos anos noventa foi tão favorável àquele ideário. Destacamos aqui alguns aspectos relevantes para a melhor compreensão dos desafios postos à transformação das práticas de saúde.

Cabe recordar que, em um contexto de tensões internas crescentes entre reformistas da Saúde e da Previdência, a VIII Conferência Nacional de Saúde se constituiu em uma arena de ampliação do debate e de retomada de uma organicidade maior da luta do movimento sanitário. Por esta razão, podemos tomar seu relatório final como a expressão do pensamento predominante no movimento sanitário na época. Ou melhor, como um reflexo das aspirações desse movimento.

Entretanto, quando contrastamos este relatório com o texto que foi aprovado, após intensas negociações com o Centrão (autodesignação do grupo conservador que se constituiu como grupo majoritário em plena Assembléia Nacional Constituinte), verificamos que a vitória do movimento sanitário, embora muito significativa, foi muito aquém das aspirações. Com efeito, na VIII Conferência, a garantia pelo Estado do direito à saúde contemplava um grande conjunto de tópicos. De fato, apenas um deles foi plenamente acolhido na constituição, mantendo exatamente a mesma redação do relatório da VIII: a garantia do direito do acesso universal e igualitário às ações e serviços de saúde. Por outro lado, o texto constitucional assegura que a saúde é livre à iniciativa privada. Ademais, no texto da Carta Magna, o SUS é definido como o conjunto de ações e serviços públicos de saúde, mas também abre o espaço para que alguns serviços privados possam dele participar em caráter complementar, a saber, aqueles (e apenas aqueles) que estabelecerem com o SUS contratos de direitos públicos. Longe das aspirações do movimento sanitário, constitui-se um arranjo no qual o SUS não é o único sistema de saúde, e sim um dos sistemas de saúde, financiado publicamente, e que convive com outros sistemas, hoje reunidos sob a rubrica da saúde suplementar. 
Essa característica tem enormes consequências. Em primeiro lugar, ela expressa, no plano normativolegal, um processo que já foi descrito como a universalização excludente: é que, à medida que o acesso à assistência médica previdenciária foi sendo ampliado, desde os anos 80 , crescentes segmentos das camadas médias da população buscaram o que hoje chamamos de saúde suplementar. Esse processo por si reduz o apoio político ao SUS.

Em segundo lugar, a coexistência da saúde suplementar, com financiamento predominantemente privado, com o SUS, faz com que este tenha de competir com o setor privado em bases de mercado pelos profissionais de saúde. Por sua vez, estes profissionais podem (e vêm fazendo) constituir estratégias de atuar concomitantemente no SUS e no setor privado. E alguns deles (sobretudo médicos altamente especializados) obtêm, em sua atuação privada, rendimentos maiores do que na sua atuação junto ao SUS. Esta dupla atuação opera no sentido de favorecer, em situações limites, a criação de uma duplicidade nas práticas: um mesmo profissional exerce práticas de distintas qualidades no SUS e no setor privado. Por fim, há que se registrar que a existência de um setor de saúde suplementar sustentase na premissa de que a qualidade das práticas no seu interior é bem superior à do SUS. A eficácia simbólica dessa premissa, mesmo que não corresponda à verdade, parece fundamental para a dinâmica da saúde suplementar.

O reconhecimento desse convívio entre o SUS e a saúde suplementar coloca questões importantes sobre os princípios da universalidade e, sobretudo, sobre o princípio da igualdade.

Podemos notar, no texto constitucional, dois sentidos da universalidade: um geral, expresso na própria idéia de que todos têm o direito à saúde (note-se que, nesse enunciado, não há, no texto constitucional, qualquer menção à equidade); o segundo, restrito ao acesso às ações e serviços de saúde. A diferença desses dois sentidos remonta exatamente à diferença entre o ideário do movimento sanitário e o acordo possível na constituinte. A questão pode ser posta da seguinte forma: reconhece-se a universalidade do direito à saúde, mas, no que diz respeito às especificações dos deveres do Estado para a garantia desses direitos, reconhece-se com absoluta clareza a obrigação do Estado em promover políticas econômicas e sociais para garantir o acesso universal às ações e serviços de saúde. Este princípio da universalidade do acesso aos serviços de saúde (permitam-me designá-lo assim para evitar confusão com a idéia mais ampla de universalidade) tem, por trás dele, uma tese ético-política: não é justo que alguém seja privado do acesso às ações e serviços de saúde dos quais necessite pelo simples fato de não ter renda. Cabe ao Estado garantir essa tese. Penso que essa tese deve ser radicalmente defendida por nós, embora ela se refira a apenas um dos componentes das necessidades de saúde das pessoas e dos grupos populacionais.

A igualdade aparece no texto constitucional ao lado da universalidade do acesso às ações e serviços de saúde. Sobre a igualdade (e aqui prefiro o termo à equidade por simples fidelidade ao texto constitucional), cabe dizer que, no texto constitucional, ela aparece no capítulo da saúde exclusivamente referindo-se ao acesso. Talvez fosse melhor denominá-la princípio do acesso igual às ações e serviços de saúde. Aqui, novamente, há um déficit entre o ideal do movimento sanitário e o texto constitucional. Vivemos numa sociedade profundamente desigual, e sonhamos com as reduções da desigualdade. O texto da Constituição reconhece que o Estado deve garantir, aos brasileiros, a igualdade do acesso aos serviços de saúde. Penso que devemos defender radicalmente esta tese ética e política, embora ela seja uma pequena parte da luta por uma sociedade mais igual. Mas cabe aqui um comentário adicional, ainda centrado no texto constitucional: o que o Estado deve assegurar é que todos os brasileiros tenham, igualmente, acesso às ações e serviços de saúde de que necessitam, e não às ações e serviços públicos de saúde que constituem o SUS. Nesse sentido, a igualdade e a universalidade do acesso não são apenas princípios do SUS, mas princípios mais gerais para a ação do Estado. Assim, a desigualdade no acesso entre brasileiros diante de uma equivalente necessidade agride o princípio constitucional. Portanto, nesse sentido, não seria aceitável a diferenciação do acesso no âmbito do SUS e na chamada saúde suplementar ${ }^{3}$. 
Nessa perspectiva, caberia refletir sobre as noções de qualidade que se colocam em jogo no debate simbólico entre o SUS e a saúde suplementar. De modo particular, cabe rejeitar a ideia de que a qualidade se expresse na simples possibilidade de consumo de bens e serviços de saúde ${ }^{4}$. A qualidade almejada deve ter, como eixo, a garantia do acesso adequado e oportuno às ações e serviços de saúde que tenham potência de responder às necessidades das pessoas, e na medida dessas necessidades.

É aqui que o princípio da integralidade pode nos oferecer uma chave para reconceitualizar a qualidade que aspiramos. Independentemente de seus múltiplos sentidos, integralidade tem a ver com a recusa às formas de reducionismo, a começar pelo reducionismo de sujeitos a objetos. Nesse sentido, reconhecer que as práticas de cuidado são necessariamente intersubjetivas, e que devem se pautar por uma perspectiva dialógica para a determinação das necessidades de ações e serviços de saúde em cada situação, tanto de grupos como de pessoas (Mattos, 2001). Diálogo que necessariamente se faz no contexto concreto dos modos de andar a vida desses grupos sociais e dessas pessoas (Mattos, 2004a, 2004b). Nesse sentido, o termo integralidade expressa um conjunto de valores que devem pautar todas as práticas de saúde, conferindo-lhes qualidades. A transformação das práticas do SUS pautadas pela integralidade, assim compreendida, abre uma perspectiva de reversão radical da imagem simbólica de qualidade superior da saúde suplementar.

Mas tomemos de modo mais restrito o sentido de integralidade que é expresso no texto da constituição: ela estabelece que o SUS deve se pautar pelo atendimento integral, com prioridade para as atividades preventivas, sem prejuízo das atividades assistenciais. Há uma diferença fundamental entre as atividades preventivas e as atividades assistenciais, que devem ser articuladas: é que estas se fazem diante de um sofrimento manifesto, enquanto aquelas se fazem antecipando-se ao sofrimento. Integralidade, no sentido evocado no texto constitucional, sugere que as ações e serviços devem se esforçar ao máximo para evitar o sofrimento, mas que não podem permitir que esse esforço se dê às custas da incapacidade de dar resposta ao sofrimento manifesto.

Penso que é em torno do sofrimento que podemos e devemos fazer o exame crítico das práticas e das instituições de saúde. O sofrimento (manifesto ou antecipado pelo conhecimento) se impõe aos serviços e aos profissionais de saúde. É ele que dá sentido às práticas do cuidado em saúde. O sofrimento é algo inerente à vida humana, como o são o cuidado e os esforços para reduzir e evitar. O sofrimento tem várias origens. Uma das características do conhecimento médico que, de certo modo, organiza atualmente as práticas de cuidado é a capacidade de conhecer os sofrimentos atribuíveis a doenças. Conhecimento esse que permite, em alguns casos, intervenções que se antecipam à vivência concreta do sofrimento atribuível à doença. O conhecimento sobre as doenças faz sentido na medida em que ele abre a possibilidade de sucessos práticos na sua superação. Contudo, o sofrimento atribuível a uma doença, tal como vivido pelas pessoas, não se dissocia dos estreitamentos no modo concreto de andar da vida. Portanto, para produzir sucessos práticos, não basta identificar a doença e mobilizar os dispositivos técnicos que permitem seu controle. Há que se contextualizar esse sofrimento e as consequências da aplicação dos dispositivos técnicos no modo de andar a vida concreto do sujeito que sofre, ou que pode vir a sofrer em consequência da doença.

Por sua vez, o contexto concreto de cada encontro entre uma pessoa e um profissional de saúde também é fundamental para que se produza um cuidado integral, pois, conforme as características específicas do contexto desse encontro,
${ }^{3}$ É claro que, sendo um princípio mais geral, também se aplica ao SUS (aliás, aplicação que fica claramente definida na Lei $n^{\circ} 8.080$ ), adquirindo aqui um significado mais restrito, embora também importante: o SUS não pode tratar diferentemente as pessoas.

${ }^{4}$ Para uma discussão mais detalhada sobre as relações das práticas de cuidado com o capital ver Mattos (2008) 
a articulação entre propostas voltadas a responder ao sofrimento manifesto e ao sofrimento antecipado pelo conhecimento precisará ser distribuída no tempo, distinguindo-se as ofertas imediatas de dispositivos de intervenção e a oferta a ser feita no futuro.

Pelo que foi exposto, é claro que não é aceitável que, por exemplo, o modo de organização dos serviços gere ou agrave por ele mesmo o sofrimento. Caberia buscar estratégias que, por levarem em conta as razões das pessoas e suas estratégias de busca dos serviços de saúde, não produzam barreiras e nem deixem sem alguma forma de resposta o sofrimento das pessoas. Sobre isso, cabe registrar que conhecemos ainda muito pouco sobre o sofrimento provocado por nossas práticas de cuidado e pelos nossos arranjos dessas práticas. Um esforço de analisar as trajetórias das pessoas e seus dramas nas relações com os serviços e profissionais de saúde pode alimentar nossos esforços de instituir novos arranjos e novas práticas.

A velha tensão entre ampliar o acesso e transformar as práticas e as instituições de saúde segue atual. Não basta garantir o acesso universal e igualitário aos brasileiros. As práticas de cuidado devem estar fortemente voltadas para dar a resposta ao sofrimento das pessoas ou para evitar esse sofrimento. É esse o desafio de um SUS mais humano. É esse o desafio de todas as políticas que se voltem especificamente para as transformações das práticas. É esse o desafio, também, da política de humanização.

Por fim, cabe lembrar que a construção desse processo de transformação tem, contudo, um significado político para a própria sustentabilidade do SUS. É que, no contexto da coexistência do SUS com a saúde suplementar, o tratamento digno das pessoas no SUS é produtor de apoio político para o SUS, da mesma forma que, cada vez que tal atendimento não ocorre, contribui-se para o sonho de alguns de virem a ter um plano de saúde. Por sua vez, a melhoria da qualidade - nesse sentido de dar respostas abrangentes e produtoras de sucessos práticos sobre o sofrimento - tensiona fortemente a coexistência do setor de saúde suplementar e, portanto, deve suscitar reações contrárias. Esta talvez seja uma luta que vale a pena travar.

\section{Referências}

BAPTISTA, T.W.F. História das políticas de saúde no Brasil: a trajetória do direito à saúde. In: MATTA, G.C.; PONTES, A.L.M. (Orgs.). Políticas de saúde: organização e operacionalização do Sistema Único de Saúde. Rio de Janeiro: EPSJV/Fiocruz, 2007. p.29-60.

CENTRO BRASILEIRO DE ESTUDOS DE SAÚDE - CEBES. A questão democrática na área de saúde. Saude em Debate, v.9, p.11-3, 1980.

FÓRUM DA REFORMA SANITÁRIA. SUS pra valer: universal, humanizado e de qualidade. Saude em Debate, v.29, n.31, p.385-96, 2006.

MATTOS, R.A. Integralidade, trabalho, saúde e formação profissional: algumas reflexões críticas feitas com base na defesa de alguns valores. In: MATTA, G.C.; LIMA, J.C.F. (Orgs.). Estado, sociedade e formação profissional: contribuições e desafios em 20 anos de SUS. Rio de Janeiro: Fiocruz, 2008. p.313-52.

Cuidado prudente para uma vida decente. In: PINHEIRO, R.; MATTOS, R.A.

(Orgs.). Cuidado: as fronteiras da integralidade. São Paulo: Hucitec, 2004a. p.119-32. 
MATTOS, R.A. A integralidade na prática (ou sobre a prática da integralidade). Cad. Saude Publica, v.20, n.5, p.1411-6, 2004b.

Os sentidos da integralidade: algumas reflexões acerca de valores que merecem ser defendidos. In: PINHEIRO, R.; MATTOS, R.A. (Orgs.). Os sentidos da integralidade na atenção e no cuidado à saúde. Rio de Janeiro: UERJ/IMS, 2001. p.39-64.

Este texto examina as relações entre os princípios do SUS e a perspectiva de transformações das práticas em saúde. O texto reconhece que, apesar da heterogeneidade do movimento sanitário, a questão da transformação das práticas de saúde tem se tornado mais importante para a sustentabilidade e legitimidade do SUS. Partindo do exame dos princípios da universalidade e equidade, examinados ao lado do princípio da integralidade, o autor defende que a categoria do sofrimento, manifesto ou não, deve ser incluída nas políticas que se voltem para a construção de práticas mais humanizadas no SUS.

Palavras-chave: Humanização da assistência. Integralidade. Práticas de saúde.

\section{Principles of the Brazilian Unified Health System (SUS) and the humanization of healthcare practices}

This paper examines the relationship between the principles of the Brazilian Unified Health System (SUS) and the perspective of transformations in healthcare practices. The text recognizes that, despite the heterogeneity of the public health movement in Brazil, the issue of transformation of healthcare practices has become more important with regard to the sustainability and legitimacy of SUS. Starting from an examination of the principles of universality and equity, alongside the principle of comprehensiveness, the author argues that the category of suffering, whether manifest or not, should be included in policies aimed at constructing practices within SUS that are more humanized.

Keywords: Humanization of assistance. Comprehensiveness. Healthcare practices.

Principios del Sistema Unico de Salud (SUS) y la humanización de las prácticas de salud

Este texto examina las relaciones entre los principios del SUS y la perspectiva de transformaciones de las prácticas en salud. Reconoce que, a pesar de la heterogeneidad del movimiento sanitario, la cuestión de la transformación de las prácticas de salud se ha vuelto más importante para el sustentamiento y la legitimidad del SUS. Partiendo del examen de los principios de universalidad y equidad, examinados al lado del principio de la integridad, el autor defiende que la categoría del sufrimiento, manifiesto o no, debe incluirse en las políticas que se dediquen a la construcción de prácticas más humanizadas en el SUS.

Palabras clave: Humanización de la atención. Integridad. Prácticas de salud. 